\title{
Petrus Johannes Theobaltus Koekemoer - teoloog saam en soos die kerk
}

\author{
S J Botha \& H G van der Westhuizen \\ Hervormde Teologiese Opleiding
}

\section{SY LEWE}

Petrus Johannes Theobaltus Koekemoer is op 27 November 1923 op die plaas Doornfontein in die distrik Klerksdorp gebore as tweede oudste seun van die egpaar J G Koekemoer. Sy skoolloopbaan begin hy op 'n plaasskool waarheen hy daagliks per donkiekar moes reis. Later verhuis die gesin na Pretoria waar hy aan die einde van 1939 aan die Hermanstadskool in standerd 8 slaag. Benouende finansiële omstandighede forseer hom om die skool te verlaat en by die Staatsdiens te begin werk. Hy sit egter sy skoolloopbaan voort deur na-uurse klasse aan die Pretoriase Tegniese Kollege by te woon en aan die einde van 1941 slaag hy matriek.

Hy tree as klerk in diens by 'n prokureursfirma waar hy smiddae werk, terwyl hy soggens aan die Universiteit van Pretoria lesings bywoon met die oog op 'n BAgraad vir die BD. In 1945 behaal hy die BA-graad en drie jaar later ook die BDgraad. Hy word egter nie dadelik predikant in die Nederduitsch Hervormde Kerk nie, maar vertrek eers na Europa waar hy aan die Universiteit van Utrecht verder studeer onder Berkelbach van der Sprenkel, A A van Ruler, J Severijn en W C van Unnik. Vir 'n semester het by ook lesings van Karl Barth in Basel bygewoon. In die eerste helfte van 1950 lê hy die doktoraaleksamen met sukses af en keer terug na Suid-Afrika.

Op 5 Augustus 1950 word hy as predikant in die Nederduitsch Hervormde Gemeente Pietersburg georden en bedien daarna agtereenvolgens ook nog die gemeentes Turffontein, Primrose, Pietersburg ( 2 keer), Bloemfontein, Rustenburg, Magaliesburg, Potchefstroom-Noord en Potchefstroom-Suid.

Gedurende hierdie tydperk werk hy aan sy proefskrif en aan die begin van 1958 promoveer hy tot doktor in die teologie met sy oud-studentemaat, prof dr B J Engelbrecht, as promotor. Die titel van sy proefskrif is Die betekenis van die Parthenogenesis in die Reformatoriese en Rooms-Katolieke dogmatiek.

Terwyl hy in Bloemfontein predikant is, doseer hy op deeltydse basis Sielkunde aan die Universiteit van die Oranje-Vrystaat. Op 1 Januarie 1979 word hy hoogleraar en hoof van die Departement Dogmatiek en Teologiese Etiek van die Her-

- Die lewe en publikasies van prof P J T Koekemoer is behartig deur prof S J Botha en die teologic deur prof $\mathrm{H} \mathrm{G}$ van der Westhuizen. 
vormde Teologiese Opleiding aan die Universiteit van die Noorde. In 1985 verskuif hy saam met die Hervormde Teologiese Opleiding na Klipdrif waar hy op 31 Augustus 1990 emeritaat aanvaar. Sy afskeidspreek lewer hy op 5 Augustus 1990 in die kerkgebou van Pietersburg waar hy presies veertig jaar tevore georden is. Hy bly egter deeltyds in diens van die Hervormde Teologiese Opleiding tot die einde van 1990 en lewer sy afskeidsrede op 13 November 1990 tydens die jaarlikse promosieplegtigheid.

Teenoor die Nederduitsch Hervormde Kerk het hy 'n baie groot liefde en lojaliteit en hy dien die kerk in verskillende liggame:

Die Kommissie van die Algemene Kerkvergadering;

Die Raad vir Bybelverspreiding (voorsitter);

Die werkgroep Gemeente-opbou (voorsitter);

Die Raad vir die herderlike sorg (voorsitter);

Die Pastorale Verwysingsdiens (voorsitter);

Die Raad vir ons Protestantse Erfenis (voorsitter);

Die Kuratoruim vir die Teologiese Opleiding aan die Universiteit van Pretoria (4 jaar voorsitter);

Die Proponentseksamenkommissie.

By geleentheid was hy ook voorsitter van die Predikantevergadering.

Tydens die Algemene Kerkvergadering van 1979 is 'n penning aan hom oorhandig vir sy aandeel aan die totstandkoming van die nuwe gesangebundel.

Prof P J T Koekemoer is op 28 Oktober 1951 getroud met mej C M (Tienie) Roos, suster van die twee bekende Roos-predikante Gert en Willie. Uit die huwelik is ses kinders, vier seuns en twee dogters, gebore. Twee van die seuns, Theo (6) en Willie (16) sterf op vroeë ouderdom.

\section{SY TEOLOGIE}

Prof dr P J T Koekemoer, deur die meeste kollegas Theo genoem, deur sommige vriende Piet genoem, deur sekere familielede en andere Petrus genoem, dateer uit die tyd toe teologiese studente van die Nederduitsch Hervormde Kerk vir verdere studie hoofsaaklik op die buiteland aangewese was.

Sy teologiese vorming wat hy aan die einde van die veertigerjare oorsee ontvang het, het hom tot nou toe verryk.

Die eerste dogmatiese invloed te Utrecht het van prof S F H J Berkelbach van der Sprenkel gekom. 'n Blywende invloed van Berkelbach op Koekemoer het ont- 
spring in Berkelbach se dogmatiese metode om sy lesings in die praktyk te laat uitmond. Berkelbach was in hierdie stadium reeds bejaard met jare se ervaring as gemeentepredikant. Dit is kenmerkend van prof Koekemoer, en hy is ook trots daarop, dat sy eie lesings hom dikwels na die Homiletiek en Poimeniek lei. Daar is wel geleerdes wat beweer dat ook Calvyn se Institutio Christianae Religionis in wese en opset Praktiese Teologie is.

Hierdie praktiese gerigtheid, en nie net alleen die feit dat Teologiese Etiek saam met Dogmatiek 'n leeropdrag aan prof Koekemoer was nie, onderbou sy omvattende aandag aan die etiek.

Miskien het nog 'n groter invloed op Koekemoer van buitestaanders gekom, van geleerdes by wie hy nooit as doktorale student formeel ingeskryf was nie. Onder hierdie persone kan Brunner, Barth en Van Ruler genoem word.

In Zürich het Koekemoer enkele lesings van Emil Brunner bygewoon. Aangesien Koekemoer in Nederland tot die besef gekom het dat die teologiese kennis van Protestantse studente oor die Roomse teologie diepgaande is en dat beide teologieë sterk in die lesingkamers figureer, het hy besluit om homself beter toe te rus ten opsigte van die Roomse teologie. ' $n$ Bepaalde teologiese debat met diepgaande aksentverskille tussen Brunner en Barth oor die parthenogenesis, was die finale prikkel om sy proefskrif hieroor te skryf.

Hierdie bepaalde studieveld het nie alleen gelei tot vele artikels ná en vanuit die proefskrif, soos in die publikasielys blyk nie, maar ook dat hy vir jare in die Nederduitsch Hervormde Kerk van Afrika diens by die rade oor Bybelverspreiding en die Roomse gevaar gedoen het. Omdat hy die Roomse invloed onder die swart gemeenskappe as van groot omvang geag het, het hy steeds in sy lesings die dwaling van die Roomse teologie benadruk.

Karl Barth se invloed het veral op drieërlei wyse 'n vormende hand op Koekemoer geplaas. Eerstens kan Berkelbach van der Sprenkel 'n gereserveerde Barthiaan genoem word. Berkelbach het natuurlik voorbehoude oor Barth se verbondsbeskouing, byvoorbeeld rondom die kinderdoop, gehad. Berkelbach se lesings, wat bestaan het uit besprekings van dele van Barth se Kirchliche Dogmatik, het bepalende inhoude aan Koekemoer besorg. Tweedens was dit Berkelbach se direkte aanbeveling aan Koekemoer om vir 'n semester in Basel aan die voete van Barth te gaan sit. Hierdie lesings wat 'n Christologiese dogmatiek aan Koekemoer tuisgebring het, met 'n toespitsing op die Versoeningsleer, was onuitwisbaar op die student uit Suid-Afrika. En dit kan bemerk word in al prof Koekemoer se teologiese bedrywighede. Derdens het Koekemoer steeds, by wyse van literatuurstudie, 'n student van Barth gebly. Dit het in sy eie Dogmatieklesings steeds neerslag gevind. 
Die grootste invloed op Koekemoer het opsigtelik van prof A A van Ruler gekom. Hy was nooit ' $n$ ingeskrewe student by Van Ruler nie, maar het soos baie ander met Van Ruler se toestemming as 'luisteraar' sy lesings oor Bybelse Teologie bygewoon.

Van Ruler is bekend daarvoor dat hy altyd helder, sensitief, genuanseerd en met diepe insig oorweldigend oortuigend sy teologie kon formuleer. Van wat hy in sy proefskrif $D e$ vervulling van de wet gesè het, het hy steeds konsekwent duidelike teokratiese riglyne getrek oor die verhouding openbaring en eksistensie.

Omdat Van Ruler se werke redelik volop in Suid-Afrika was en is en veral in die Nederduitsch Hervormde Kerk, wat ook soos Van Ruler 'n volkskerkbeskouing handhaaf, het Koekemoer hom steeds verder met Van Ruler verryk. Self vertel hy dikwels die staaltjie van die goeie Hollandse gemeentelid in een van sy gemeentes wat eerder by 'n buurgemeente kerk toe gegaan het. Op navraag was sy argument dat as hy Van Ruler wil hoor sal hy eerder hom self lees!

Aangesien Koekemoer na die doktoraaleksamen te Utrecht sy proefskrif in Pretoria onder die feitlik ewe jong prof dr B J Engelbrecht kom doen het, het laasgenoemde ook blywende invloed op die promovendus uitgeoefen. Soos elders in hierdie HTS genoem word, het prof Koekemoer dogmatiek a la sola Scriptura bedryf. Hierdie Skrifgefundeerdheid met 'n sterk Calvyninslag om kerklike ofte wel konfessionele dogmatiek te bedryf, is perspektiewe wat Engelbrecht blywend by Koekemoer vasgelè het.

\section{SY PUBLIKASIES}

Die volgende is 'n lys van publikasies van prof Koekemoer wat opgespoor kon word, maar wat waarskynlik nie volledig is nie:

\section{Wetenskaplike publikasies in Hervormde Teologiese Srudies}

1. Terreinverkenning insake die verhouding tussen psigoterapie en sielsorg. HTS 20/2, 1964.

2. R Bultmann: Nie saam met die kerk en soos die kerk nie. HTS 21/1, 1965 .

3. Karl Barth se beskouing ten opsigte van die leer van die Parthenogenesis met 'n verwysing na die etiese ideaal van die ongehude staat. HTS 22/4, 1966.

4. In Memoriam: Prof dr S F H J Berkelbach van der Sprenkel. HTS 23/1, 1968.

5. Kritiek teen Artikel 3 van die Apostolicum. HTS 26, 1970.

6. Die Getuienis van die Evangelie volgens Matheus oor die maagdelike geboorte van Jesus Christus. HTS 28/2, 1972.

7. Tekskritiek en die Sola Scriptura. HTS 28/3 \& 4, 1972. 
8. Die Parthenogenesis in die Apostolicum en die Symbolum-Niceno-Constantinopolitanum. HTS 29/3, 1973.

9. Die Rooms-Katolieke leer, sin en betekenis van Artikel 3(b) van die Apostolicum. HTS 29/4, 1973.

10. Die Reformatoriese dogmatiese bevestiging van die Parthenogenesis in enkele belangrike konfessies en leerboeke. HTS 30/1 \& 2, 1974.

11. Wat leer Calvyn en Luther oor die maagdelike geboorte van Jesus Christus? HTS 31/1 \& 2, 1975.

12. Die ontkenning van die leer van die maagdelike geboorte deur Menno Simons, Emil Brunner en R Bultmann. HTS 31/3 \& 4, 1975.

13. Die dogmatiese kontrovers tussen Rooms-Katolisisme en Protestantisme ten opsigte van die mariologiese dogma, Skrif en tradisie. HTS 32, 1976.

14. Die psigoanalise van Sigmund Freud: Oorsig en kritiese opmerkinge. HTS 33/1 \& 2, 1977.

15. Boekbespreking - G Th Rothuizen: Preeken. HTS 33/3 \& 4, 1977.

16. Henormde Teologiese Studies (Studia Theologica Varia). S P J J van Rensburg dedicata (1972), Die maagdelike geboorte van Jesus Christus volgens die Nuwe Testament.

17. Hervormde Teologiese Studies. Jubileum uitgawe - Prof dr B J Engelbrecht (1976), Pastoraat vir die bejaardes.

18. Boekbespreking - J H Cornelder: Karl Barth aan de hand van zijn brieven en auto-biografisch teksten. HTS 36/1 \& 2, 1980.

19. Boekbespreking - J J F du Rand: Skepping, mens, voorsienigheid. HTS 38/2 \& 3, 1982.

20. Boekbespreking - A A Alders et al: Barth - Kolbrugge - Miskotte: Ontwikkeling of breuk? HTS 41/3, 1985.

21. Boekbespreking - B Engelbrecht: Die tweeheid van kerk en staat. HTS 43/3, 1987.

22. Padveiligheid: Teologies-etiese opmerkings by enkele navorsingsprojekte in verband met die verkeersituasie in die R S A. HTS 44/2, 1988.

\section{Ander wetenskaplike publikasies}

1. 'Ons Protestantse erfenis', in die reeks Kerk en Reformasie. Pretoria: HAUM.

2. Die Teologies-etiese probleem van die eutanasie met verwysing na die Mediese

Etiek. Intreerede by die aanvaarding van die leerstoel in Dogmatiek en Teologiese Etiek aan die Universiteit van die Noorde. 6 Augustus 1980. Uitgegee deur die Universiteit van die Noorde. 
3. Bedienaars van die Woord en bedienaars van Woord-en-sakramente? Hoofstuk in Die kerk in die wêreld, HAUM Uitgewers 1982.

4. Selfmoond 1983. Pretoria: Kital.

5. Dogmatiese binding in die prediking met besondere verwysing na die Kategismusprediking, in Die prediking 1984. NHW Pers.

6. Pastoraal-psigologiese opmerkings oor bystand aan sterwendes. Theologia Viatorum $9 / 2$ (1981).

7. Geloof en kennis in onderlinge verband. Theologia Viatorum 12/2 (1984).

8. Luther se regverdigingsleer in gedrang! Vrae aan Luther se Kerk, in Martin Luther 1483-1546. 1984. Kital.

9. Die barmhartigheidsdiens: 'n Sistematies-teologiese evaluering, in Die barmhartigheidsdiens. 1985. NHW Pers.

10. Gebed en genesing, in Kerk en sekte. 1970. Pretoria: HAUM.

\section{Artikels in Die Henormer}

1. Mei 1950. 'Wij Gereformeerden....'

2. Julie 1950. Die ontstaan van die Gereformeerde Kerke in Nederland (Artikel 31).

3. Februarie 1951. Die mens as getuie van God.

4. Desember 1951. Openingsrede by die Ring van Soutpansberg.

5. Maart 1952. Kerk en wêreld.

6. April 1952. 'n Brief van Calvyn uit Basel aan die owerheid.

7. Junie 1953. 'En julle sal my getuies wees'.

8. November 1953. Dr Budmann se voorgenome besoek aan ons land.

9. November 1955. Benjamin, seun van smarte en blydskap.

10. April 1959. Versigtigheid is die 'moeder der wysheid'.

11. September 1959. Seënwense oorgebring aan die Sinode van die Lutherse Kerk.

12. September 1959. Die boodskap van ds H J Hegger.

13. Oktober 1959. 'Die geestelike moeder'...boodskap van ds H J Hegger.

14. November 1959. Die Roomse Kerk strewe na mag....

15. Januarie 1960. 'Hy wat hom afskei soek sy eie begeerte' (Spreuke 18:1).

16. Januarie 1961. Die ontlediging van die vleeswording van die Woord.

17. Februarie 1961. Ons jeugwerk.

18. Maart 1961. Die opgewondenheid oor die kritiek op Artikel 3, waarom?

19. Maart 1964. Want dit is geen besondere kuns nie....

20. Mei 1964. Die oudag: 'n Sielkundige benadering.

21. Desember 1964. Naomi en Rut. 
22. Februarie 1965. 'Genesing' in die groot tent?

23. Julie 1965 . Om ouderling te wees....

24. November 1965. 'n Kerk: radeloos, luisterend, biddend!

25. Oktober 1967. Met watter gesag spreek die kerk dan wel?

26. September 1968. Uit die geskiedenis van die ouderlingamp.

27. Oktober 1968. Die Roomse Kerk praat nou ook Afrikaans.

28. November 1968. Maria in die Bybel.

29. Maart 1969. By die heengaan van Karl Barth.

30. Maart 1969. Die 1969 Almanak en Bybelse Dagboek.

31. Maart 1970. Die 1970 Almanak en Bybelse Dagboek.

32. April 1970. J G Benade en seun: Twee staatmakers.

33. Junie 1970. Die S A Bybelgenootskap 150 jaar in Suid-Afrika.

34. Oktober 1970. 'Here, leer ons bid': Die grond van die gebed.

35. September 1970. 'Here, leer ons bid'.

36. Desember 1970. 'n Ou boodskap aan die moderne, mondige mens.

37. Januarie 1971. Hoe bid ons?

38. Februarie 1971. Almanak en Bybelse Dagboek 1971.

39. Maart 1971. 'Here, leer ons bid'.

40. April 1971. Kuratorium vir die Teologiese Opleiding.

41. April 1971. 'Here, leer ons bid'.

42. April 1972. As toeris deur Israel....

43. Mei 1972. Die blinde man van Jerigo.

44. Mei 1972. Die Fariseër en die Tollenaar.

45. Mei 1972. Die Olyfberg en Getsemane.

46. Junie 1972. Die Via Dolorosa.

47. Julie 1972. Waar is Golgota en die Heer se graf?

48. Augustus 1972. Die sogenaamde 'Tuingraf'.

49. September 1972. Die Dooiesee-rolle.

50. Oktober 1972. Die meer van Tiberias.

51. November 1972. Die Dooie-see.

52. Desember 1972. Bethlehem.

53. Januarie 1973. Nasaret.

54. Februarie 1973. Cesarea.

55. Maart 1973. Masada.

56. April 1973. Kapernaum.

57. Mei 1973. Megiddo (Armageddon).

58. Junie 1973. Die Samaritane.

59. Julie 1973. Die Samaritane (vervolg). 
60. Augustus 1973. Jerigo.

61. September 1973. Die Jordaandal.

62. Oktober 1973. Hebron.

63. November 1973. Joppe.

64. Desember 1973. Jerusalem.

65. Desember 1973. J Velema: Blijven belijden (resensie).

66. Januarie 1974. Jerusalem (vervolg).

67. Februarie 1974. Jerusalem (vervolg).

68. Maart 1974. Jerusalem (vervolg).

69. April 1974. Jerusalem (vervolg).

70. Mei 1974. Die sogenaamde 'Klaagmuur'.

71. Junie 1974. 'Jerusalem, stad van oorloë'.

72. Julie 1974. 'n Watertonnel uit die dae van koning Hiskia.

73. Julie 1974. Gesprek tussen diaken en lidmaat.

74. Augustus 1974. Die Burg van Dawid.

75. Augustus 1974. 'Die God sorg vir ons' (oordenking).

76. September 1974. Die rotskoepel.

77. Oktober 1974. Die moskee van El-Aksa.

78. November 1974. Die Hebreeuse Universiteit en 'Ein Karem'.

79. Desember 1974. Sinai.

80. Januarie 1975. 'Nie slegs melk en en heuning nie.'

81. Februarie 1975. Studie en skole op die plaas (kibboets).

82. Maart 1975. Toer deur Israel is geen 'yyfde Evangelie' nie.

83. April 1975. Ons Tehuise vir bejaardes.

84. April 1975. Korinthe.

85. Mei 1975. Korinthe (vervolg).

86. Mei 1975. Leerstellinge: Opmerkings oor ons Gesange.

87. Mei 1975. Ken ons hulle goed? (Ons bejaardes).

88. Junie 1975. Korinthe (vervolg).

89. Junie 1975. Ken ons hulle goed? (Ons bejaardes).

90. Julie 1975. Die ou Bybelstad, Athene (1).

91. Julie 1975. Ken ons hulle goed? (Ons bejaardes).

92. Augustus 1975. Die ou Bybelstad, Athene (2).

93. Augustus 1975. Ons bejaardes: Ken ons hulle goed?

94. September 1975. Die ou Bybelstad, Athene (3).

95. Oktober 1975. Genève, stad van Calvyn (1).

96. Oktober 1975. Ons bejaardes: Ken ons hulle goed?

97. November 1975. Ons bejaardes: Ken ons hulle goed? 
98. November 1975. Genève, stad van Calvyn (2).

99. November 1975. Ons praat oor opsig en tug.

100. Desember 1975. Genève, stad van Calvyn (3).

101. Desember 1975. Ons bejaardes: Ken ons hulle goed?

102. Januarie 1976. Ons bejaardes: Gesprek met hulle.

103. Februarie 1976. Die ou Rome (1).

104. Februarie 1976. Ons bejaardes: Ken ons hulle goed?

105. Maart 1976. Die Kerkstaat, Vatikaanstad.

106. Maart 1976. Ons bejaardes: Ken ons hulle goed?

107. April 1976. Die katekombes en Via Appia.

108. Mei 1976. Ons bejaardes: Ken ons hulle goed?

109. Junie 1976. 'Die reuk van sy kennis' deur ds D S Jacobs (resensie).

110. Junie 1977. Argeologiese opgrawings in Jerusalem: Waarom juis hier gebou?

111. Julie 1977. Waar is die ou Bybelse Jerusalem?

112. Augustus 1977. Jebus.

113. September 1977. Waarom dan 'n halwe Bybel?

114. Oktober 1977. 'En die Skrif nie gebreek mag word nie...' (Joh 10:35).

115. Oktober 1977. Verdere ontdekkings op die Ophel.

116. November 1977. Waarom dan 'n halwe Bybel?

117. November 1977. Jerusalem: Waters van Gihon.

118. Desember 1977. Hiskia se watertonnel.

119. Desember 1977. Die doodstraf - ja of nee?

120. Januarie 1978. Die Joodse Qumraanbroederskap (1).

121. Februarie 1978. Die doodstraf - ja of nee?

122. Februarie 1978. Die Joodse Qumraanbroederskap (2).

123. Maart 1978. Die doodstraf - ja of nee?

124. April 1978. Herodion, fort en graf van die kindermoordenaar.

125. April 1978. Beit-Shean of Bet Shan?

126. Mei 1978. Hasor.

127. Junie 1978. Die doodstraf - ja of nee?

128. Augustus 1978. Die kerk se Pastorale Verwysingsdiens.

129. September 1978. Die doodstraf - ja of nee?

130. Oktober 1978. Die wording van ons nuwe Psalm- en Gesangeboek (enkele opmerkings).

131. Januarie 1980. Die slagting op ons paaie: Wat behoort die kerk te sê?

132. Mei 1980. Selfmoord: Wat se die kerk?

133. Junie 1980. Selfmoord! Die kerk se roeping.

134. Maart 1983. Psalm 146: 'n Beryming. 
135. Mei 1983. Wyle ouderling Klaas Berkenbosch.

136. Mei 1983. Kan Hemelvaartsdag werklik 'n feesdag wees?

137. Oktober 1983. Nuwe Psalmberyming in historiese oorsig.

138. November 1983. 'n Nuwe Psalmberyming 110 jaar oud.

139. Januarie 1984. Bybelverspreiding as een van die grootste take van die Christelike Kerk.

140. Februarie 1984. Ons Pastorale Verwysingsdiens vervul in 'n groot behoefte.

141. Oktober 1986. Die nuwe Rooms-Katolisisme (1).

142. November 1986. Die nuwe Rooms-Katolisisme (2).

143. Oktober 1987. A A van Ruler oor die volkskerk.

144. Februarie 1988. Die onrusbarende sterftesyfer op ons paaie en strate.

145. Mei 1988. Oor die gedrag op ons paaie en strate durf die kerk nie swyg nie.

146. Junie 1988. Ons Christelike geloof moet bevestig word ook op ons paaie en strate.

147. Julie 1988. Hoe kan ons die duisende verkeersbotsings verminder?

148. Oktober 1988. Alkoholbetrokkenheid by verkeersbotsings.

149. November 1988. Dr Herman Wiersinga en die probleem van menslike lyding.

150. Oktober 1989. Genadedood en die teologie ter perse (op versoek van die redakteur van Die Hervormer). Twee artikels: 1. In die smeltkroes van staatkundige problematiek moet die kerk steeds kerk bly. 2. Betrek meer en meer die gemeente in die dienswerk van die Heer van die Kerk: Die gemeente 'Die sout vir die aarde' (Matt 5:13).

\section{Artikels in Die Christelike Vrou}

1. Vanaf Maart 1975 tot Februarie 1976 - elf artikels oor die 'Wet van die Here:

Laat my nie afdwaal van u gebooie nie.'

2. September 1987. Eers 'Die Blye Boodskap', nou ook die sogenaamde 'Lewende Nuwe Testament?'

3. September 1978. In Memoriam: Ds Willie Huyzers.

4. September 1978. Welvaart en luiheid.

5. Oktober 1978. Welvaart en luiheid. 